\title{
Quantification of ${ }^{18}$ F-JNJ-42259152, a Novel Phosphodiesterase 10A PET Tracer: Kinetic Modeling and Test-Retest Study in Human Brain
}

\author{
Koen Van Laere ${ }^{1}$, Rawaha U. Ahmad ${ }^{1}$, Hendra Hudyana ${ }^{1}$, Kristof Dubois ${ }^{2}$, Mark E. Schmidt ${ }^{2}$, Sofie Celen ${ }^{3}$, \\ Guy Bormans ${ }^{3}$, and Michel Koole ${ }^{1}$ \\ ${ }^{I}$ Department of Imaging and Pathology, Nuclear Medicine, University Hospital and KU Leuven, Leuven, Belgium; ${ }^{2}$ Janssen Research \\ and Development, Janssen Pharmaceutica, Beerse, Belgium; and ${ }^{3}$ Laboratory for Radiopharmacy, KU Leuven, Leuven, Belgium
}

Phosphodiesterase 10A (PDE10A) plays a central role in striatal signaling and is implicated in several neuropsychiatric disorders, such as movement disorders and schizophrenia. We performed initial brain kinetic modeling of the novel PDE10A tracer ${ }^{18} \mathrm{~F}-\mathrm{JNJ}-$ 42259152 (2-[[4-[1-(2-18F-fluoroethyl)-4-(4-pyridinyl)-1H-pyrazol-3yl]phenoxy]methyl]-3,5-dimethyl-pyridine) and studied test-retest reproducibility in healthy volunteers. Methods: Twelve healthy volunteers (5 men, 7 women; age range, 42-77 y) were scanned dynamically up to $135 \mathrm{~min}$ after bolus injection of $172.5 \pm 10.3 \mathrm{MBq}$ of ${ }^{18} \mathrm{~F}-J N J 42259152$. Four volunteers (2 men, 2 women) underwent retest scanning, with a mean interscan interval of $37 \mathrm{~d}$. Input functions and tracer parent fractions were determined using arterial sampling and high-performance liquid chromatography analysis. Volumes of interest for the putamen, caudate nucleus, ventral striatum, substantia nigra, thalamus, frontal cortex, and cerebellum were delineated using individual volumetric T1 MR imaging scans. Onetissue (1T) and 2-tissue (2T) models were evaluated to calculate total distribution volume $\left(\mathrm{V}_{\mathrm{T}}\right)$. Simplified models were also tested to calculate binding potential $\left(\mathrm{BP}_{\mathrm{ND}}\right)$, including the simplified reference tissue model (SRTM) and multilinear reference tissue model, using the frontal cortex as the optimal reference tissue. The stability of $\mathrm{V}_{\mathrm{T}}$ and $\mathrm{BP}_{\mathrm{ND}}$ was assessed down to a $60-\mathrm{min}$ scan time. Results: The average intact tracer half-life in blood was $90 \mathrm{~min}$. The $2 \mathrm{~T}$ model $\mathrm{V}_{\mathrm{T}}$ values for the putamen, caudate nucleus, ventral striatum, substantia nigra, thalamus, frontal cortex, and cerebellum were $1.54 \pm 0.37,0.90 \pm 0.24,0.64 \pm 0.18,0.42 \pm 0.09,0.35 \pm$ $0.09,0.30 \pm 0.07$, and $0.36 \pm 0.12$, respectively. The $1 \mathrm{~T}$ model provided significantly lower $V_{T}$ values, which were well correlated to the 2T $\mathrm{V}_{\mathrm{T}}$. SRTM BP $\mathrm{ND}$ values referenced to the frontal cortex were $3.45 \pm 0.43,1.78 \pm 0.35,1.10 \pm 0.31$, and $0.44 \pm 0.09$ for the respective target regions putamen, caudate nucleus, ventral striatum, and substantia nigra, with similar values for the multilinear reference tissue model. Good correlations were found for the target regions putamen, caudate nucleus, ventral striatum, and substantia nigra between the $2 \mathrm{~T}$-compartment model $\mathrm{BP}_{\mathrm{ND}}$ and the SRTM $\mathrm{BP}_{\mathrm{ND}}\left(r=0.57,0.82,0.70\right.$, and 0.64 , respectively). SRTM BP $\mathrm{ND}_{\mathrm{N}}$ using a 90- and 60-min acquisition interval showed low bias. Test-retest variability was $5 \%-19 \%$ for $2 \mathrm{~T} \mathrm{~V}_{\mathrm{T}}$ and $5 \%-12 \%$ for $\mathrm{BP}_{\mathrm{ND}} \mathrm{SRTM}$. Conclusion: Kinetic modeling of ${ }^{18} \mathrm{~F}-J \mathrm{NJ}-42259152$ shows that PDE10A activity can be reliably quantified and simplified using a reference

Received Dec. 17, 2012; revision accepted Mar. 26, 2013.

For correspondence or reprints contact: Koen Van Laere, Department of Imaging and Pathology, Nuclear Medicine, KU Leuven and UZ Leuven, Herestraat 49, 3000 Leuven, Belgium.

E-mail: koen.vanlaere@uzleuven.be

Published online Jul. 10, 2013.

COPYRIGHT $\odot 2013$ by the Society of Nuclear Medicine and Molecular Imaging, Inc. tissue model with the frontal cortex as reference and a 60 -min acquisition period.

Key Words: PDE10A; PET; radioligand; ${ }^{18} \mathrm{~F}$; phosphodiesterase

J Nucl Med 2013; 54:1285-1293

DOI: 10.2967/jnumed.112.118679

$\mathbf{P}$ hosphodiesterase 10A (PDE10A) is a dual-substrate enzyme with a restricted distribution, predominantly in the human brain in medium spiny neurons of the striatum, the substantia nigra, the nucleus accumbens and olfactory tuberculum (1), and-to a much lower extent-the hippocampus and cerebral cortex (1,2). PDE10A hydrolyzes the important second messengers cyclic adenosine monophosphate (cAMP) and cyclic guanosine monophosphate, with an approximately 20-times higher affinity for cAMP $(3,4)$. Through hydrolysis of cAMP, PDE10A downregulates protein kinase A activity, which relies on CAMP for activation and regulates the phosphorylation of various intracellular targets downstream of protein kinase A such as DARPP-32 as an integrator of dopamine and glutamate signals (5). This role in striatal signaling has made PDE10A an enzyme of particular interest because it is likely involved in several neuropsychiatric disorders. This hypothesis is supported by preclinical studies with PDE10A inhibitors, showing that pharmacologic inhibition of PDE10A leads to activation of medium spiny neurons (MSNs) and alteration of behavioral aspects modulated by the striatal circuit (6). Disruption of the conditioned avoidance response, an established preclinical model for antipsychotic activity, was observed after the administration of PDE10A inhibitor TP-10 (7) and MP-10 (8), and reduced exploratory locomotor activity was seen (7). Such pharmacologic alterations were not found in PDE10A knockout mice (9). PDE10A inhibition may constitute a new approach for the treatment of disorders with altered activity of medium spiny neurons, such as schizophrenia (8), Huntington disease (10), and addiction (11).

A suitable PDE10A tracer that allows in vivo quantification of PDE10A would lead to a better understanding of the role of PDE10A activity in health and disease, can be used as a tool for early clinical evaluation of emerging PDE10A medication, and may also present new diagnostic opportunities. Several attempts to quantify PDE10A using PET have been recently published. ${ }^{11} \mathrm{C}-\mathrm{MP}-10$ has been evaluated in nonhuman primates $(2,12)$, but although it showed good affinity and high selectivity for PDE10A, a lipophilic radiolabeled metabolite hampered further human 
application. The preclinical evaluation of ${ }^{11} \mathrm{C}$-papaverine in rhesus macaques showed low retention (13). We previously evaluated ${ }^{18} \mathrm{~F}$-JNJ41510417 in PDE10A knockout and wild-type mice and in rodents (14). Although this tracer showed high selectivity and affinity, in vivo brain kinetics were slow, hampering accurate quantification. Therefore, it was decided to investigate other candidates based on similar leads. ${ }^{18} \mathrm{~F}-\mathrm{JNJ}-42259152$, or 2-[[4[1-(2- ${ }^{18}$ F-fluoroethyl)-4-(4-pyridinyl)-1H-pyrazol-3-yl]phenoxy]methyl]3,5-dimethyl-pyridine, is also an antagonist of PDE10A-with a lower half-maximal inhibitory concentration of $1.6 \mathrm{nM}$ (15), a low polar surface area, and a plasma protein binding of $99.5 \%$ and is 1,000-fold more selective than for the other phosphodiesterase enzymes (Janssen Research and Development, unpublished data, 2011). In humans, a first-in-man biodistribution and dosimetry study showed that the tracer was safe and displayed promising kinetics for further quantitative evaluation of PDE10A activity in the nigrostriatal circuit (16).

The aim of this study was to perform full brain kinetic modeling of ${ }^{18} \mathrm{~F}-\mathrm{JNJ}-42259152$ and study test-retest reproducibility in healthy human volunteers. Additionally, we evaluated the simplified reference region model to investigate the possibility of noninvasively quantifying PDE10A and reducing acquisition time to allow clinical application in a variety of neuropsychiatric patient populations.

\section{MATERIALS AND METHODS}

\section{Subjects}

Healthy subjects aged $40-80$ y were recruited for this monocentric, academic study through advertisements in a local community newspaper and on the departmental Web site. All subjects were screened for neuropsychiatric and other medical disorders and were subjected to a physical examination, blood and urine testing (including toxicology for drugs), and structural brain MR imaging. Subjects who were current users of any illicit drugs (including recreational use) or had any history of drug or alcohol abuse were excluded. A history of tobacco use was also reason for exclusion unless the subject had completely stopped for at least 3 mo. No medication use was allowed.

In total, 12 healthy volunteers ( 5 men, 7 women) between the ages of 42 and 77 y (mean age \pm SD, $57.8 \pm 10.3$ y) were included. To determine test-retest reliability over a period of weeks, 4 of these subjects ( 2 men, 2 women; mean age $\pm \mathrm{SD}, 61.5 \pm 13.9$ y) underwent a second PET scan. Written informed consent was obtained from all the volunteers before participation. The study was approved by the local Ethics Committee and performed in accordance to the latest version of the World Medical Association Declaration of Helsinki.

\section{Radiotracer Preparation}

The precursor for tracer synthesis was obtained from Janssen Research and Development. Radiolabeling was performed on-site using ${ }^{1-18} \mathrm{~F}$-fluoro-2-bromoethane, which was distilled into the precursor solution (containing $\mathrm{Cs}_{2} \mathrm{CO}_{3}$ in anhydrous dimethylformamide). The reaction mixture was injected onto a high-performance liquid chromatography (HPLC) system eluted with a mixture of sodium phosphate $(0.01 \mathrm{M}$, $\mathrm{pH} 2.2$ ) and ethanol (15). The radiochemical purity was more than $95 \%$, and specific activity was always higher than $100 \mathrm{GBq} / \mu \mathrm{mol}$ (mean $\pm \mathrm{SD}, 222 \pm 156 \mathrm{GBq} / \mu \mathrm{mol}$; range, $110-534 \mathrm{GBq} / \mu \mathrm{mol}$ ). In this study, the mean administered mass dose was $0.52 \pm 0.38 \mu \mathrm{g}$.

\section{Pharmacologic Properties of JNJ-42259152}

JNJ-42259152 is a potent and highly selective inhibitor of PDE10A. JNJ-42259152 inhibits the cAMP-hydrolyzing activity of purified recombinant PDE10A with potency pIC50 (known log of inhibition constant at $50 \%$ ) of 8.82 for the human enzyme. JNJ-42259152 is more than 1,000-fold more selective for PDE10A, relative to all other human phosphodiesterases. Various radioligand binding experiments (including CEREP standard binding profiling) indicated that JNJ-42259152 at a concentration of $10 \mu \mathrm{M}$ did not show affinity for most of the human receptors, ion channels, or transporters (Janssen Research and Development, unpublished data, 2011). In vivo blocking and displacement studies conducted in rats are the subject of a future preclinical evaluation study to be described elsewhere (17).

\section{Imaging Procedure and Safety Assessments}

All subjects were scanned on a HiRez Biograph 16 PET/CT camera (Siemens) in 3-dimensional mode. For reasons of standardization, subjects fasted for $4 \mathrm{~h}$ before PET. They received a fast bolus injection of $173.5 \pm 6.3 \mathrm{MBq}$ of ${ }^{18} \mathrm{~F}-\mathrm{JNJ}-42259152$. The dynamic PET brain scan was initiated simultaneously with the radiotracer bolus injection and consisted of 2 scanning segments. The first 90-min segment started on tracer injection, and the second 30-min segment started at 105 min after injection. Both segments were acquired in list-mode. A low-dose CT scan (80-kV tube potential, $11 \mathrm{mAs}$ ) was obtained at the beginning of both PET acquisition segments for attenuation correction.

Test-retest reproducibility was evaluated in 4 healthy volunteers. The interval between scanning was $26.3 \pm 10.5 \mathrm{~d}$.

For reconstruction, the first segment of each PET scan was rebinned in 26 frames with progressively increasing frame durations $(4 \times 15,4$ $\times 60,2 \times 150$, and $16 \times 300 \mathrm{~s}$ ), with a total duration of $90 \mathrm{~min}$. The second segment was rebinned in 6 frames of $300 \mathrm{~s}$. All frames were Fourier-rebinned and reconstructed using an ordered-subset expectation maximization algorithm with 5 iterations and 8 subsets and a uniform gaussian postsmoothing filter of $5 \mathrm{~mm}$. The reconstructed volume consisted of 81 slices of 2-mm thickness with a matrix size of $128 \times 128$ and reconstructed pixel size of $2 \mathrm{~mm}$. Emission data were corrected for attenuation and scatter.

As part of the screening and for further anatomic coregistration with PET to delineate volumes of interest, volumetric magnetization prepared rapid acquisition gradient-echo $\mathrm{T} 1$ (repetition time, $0 \mathrm{~ms}$; echo time, $4 \mathrm{~ms}$; flip angle, $12^{\circ}$; inversion time, $300 \mathrm{~ms}$; matrix, $256 \times 256$; 160 sagittal contiguous slices of $1 \mathrm{~mm}$ ) and standard T2 MR images were obtained.

To further assess the safety of ${ }^{18} \mathrm{~F}-\mathrm{JNJ}-42259152$ administrations, before and after the PET acquisition a physical examination (including blood pressure measurement and neurologic evaluation), laboratory blood analyses (which included blood cell counts and liver and kidney function tests), and electrocardiography were performed. An electrocardiogram and blood pressure measurements were also taken at other predefined time points during the PET acquisition. All adverse experiences were monitored during and immediately after the PET scan (follow-up monitoring after the procedure comprised a telephone interview at 24 and $14 \mathrm{~d}$ after scanning).

\section{Plasma Input Curve and Metabolite Determinations}

In all subjects, arterial and venous blood sampling was performed manually through an arterial and venous cannula in the lower radial artery and an antecubital vein, respectively (in the opposite arm of injection), to determine the arterial input function curve and radiometabolite fraction, determined both in arterial and venous blood. Per imaging session, 2-mL arterial samples were drawn at the following times: every $10 \mathrm{~s}$ for the first $100 \mathrm{~s}$; at 120,140, and $160 \mathrm{~s}$ after injection; and at $3,4,5,8,10,15,20,30,40,60,90$, and $120 \mathrm{~min}$ after injection. Additional 5-mL blood samples (both arterial and venous) were drawn at 5, 10, 20, 40, 90, and $120 \mathrm{~min}$ for metabolite measurement. All samples were immediately placed on ice before analysis.

Blood samples were centrifuged for $10 \mathrm{~min}$ at 3,000 rotations per minute. Authentic JNJ-42259152 $(10 \mu \mathrm{g})$ was added to $0.8-\mathrm{mL}$ of plasma, and the mixture was then injected onto the HPLC system as such. The HPLC eluent was collected in 3 fractions: $2-5$ min, $10-12 \mathrm{~min}$ (metabolite fractions), and 13-16 min (parent fraction). A $\gamma$-counter 
(1480 Automatic $\gamma$-counter Wallac Wizard 3; PerkinElmer) was used to measure the amount of radioactivity in each fraction.

\section{Image Analysis and Kinetic Modeling}

Motion correction was performed on the dynamic dataset using PMOD (PMOD Inc.) (with sum of squared differences minimization algorithm). The retest PET scan was rigidly registered to the first PET scan and subsequently to the individual MR images (using normalized mutual information and the first 16 image frames). Three-dimensional volumes of interest were then manually delineated on individual MR images for the following brain regions: caudate nucleus, putamen, ventral striatum, substantia nigra, medial frontal cortex, thalamus, and cerebellum. The latter 3 regions were considered as potential reference regions with low PDE10A expression (1).

Tissue Distribution Volume and Metabolite Kinetics. The rate of tracer metabolism was modeled by fitting $(1-\mathrm{A})+\mathrm{A} \times \exp (-\ln (2) \times$ $\mathrm{t} / \mathrm{B})$ to the parent fraction $\mathrm{f}_{\text {parent }}(\mathrm{t})$, where $\mathrm{A}(0<\mathrm{A}<1)$ represents a fast exponential metabolizing component with corresponding halflife B. This way, a parent fraction estimate was available for each time point of the arterial plasma activity samples. Using the corresponding parent fraction estimates, we subdivided arterial plasma activity samples into activity values for the intact tracer fraction and a potential metabolite fraction. This way, 2 arterial input functions were generated: a metabolite-corrected arterial input function for modeling intact tracer kinetics and a metabolite arterial input curve that can be used to model metabolite kinetics.

To quantify regional tracer kinetics, total distribution volumes $\mathrm{V}_{\mathrm{T}}$ (18) were estimated using a standard 1-tissue-compartment model (1TCM) and 2-tissue-compartment model (2TCM) together with a radiometabolite-corrected arterial input function. Time-activity curve data points were weighted according to frame duration and radioactive decay.

Because initial results showed that a $2 \mathrm{TCM}$ was preferable to a 1TCM for describing tracer kinetics of brain regions with presumably low PDE10A expression, we evaluated 3 possible assumptions to further investigate these findings.

A first assumption was that a $2 \mathrm{TCM}$ was needed for appropriate modeling of a small fraction of specific binding $\left(2 \mathrm{TCM}_{[\mathrm{spec}]}\right)$. A second hypothesis was that an aspecific tracer binding with slower kinetics would require a $2 \mathrm{TCM}\left(2 \mathrm{TCM}_{[\mathrm{aspec}]}\right)$. Although both assumptions use a mathematically equivalent $2 \mathrm{TCM}$, boundary conditions in terms of constraints applied to the 2TCM rate constants are different.

In the case of $2 \mathrm{TCM}_{[\mathrm{spec}]}$, the 2 compartments representing free tracer and nonspecific binding of a 3-tissue-compartment model (3TCM) were merged into 1 compartment representing the nondisplaceable distribution volume $\mathrm{V}_{\mathrm{ND}}$ (Fig. 1). This simplification corresponds to the most commonly used interpretation of 2TCM. Because specific binding is modeled by a separate compartment, $\mathrm{V}_{\mathrm{ND}}$ corresponding to $K_{1} / k_{2}$ was estimated for the frontal cortex and considered constant for the target and other potential reference regions. Other 2TCM parameters$K_{1}, k_{3}$, and $k_{4}$, and therefore $\mathrm{V}_{\mathrm{S}}$ (distribution volume for specific binding)—were estimated independently for each brain region.

For the $2 \mathrm{TCM}_{\text {[aspec] }}$ hypothesis, we used an approach as proposed by Watabe (Hiroshi Watabe, written communication, 2012), where kinetic behavior in the reference tissue is described on the basis of 2 tissue compartments: one for free tracer and one for nonspecific binding. Basically, this means that 2 compartments of the 3TCM representing, respectively, free tracer and specific binding, can be merged and the remaining 2TCM compartment represents nonspecific binding (Fig. 1). Assuming that the amount of nonspecific binding in reference and target tissues was the same, the distribution volume for the remaining tissue compartment representing nonspecific binding was estimated for the frontal cortex and set to this value for both target and other potential reference regions. No further restrictions were applied to other $2 \mathrm{TCM}$ parameters $K_{1}, k_{2}$, and $\mathrm{k}_{3}$, and therefore $\mathrm{V}_{\mathrm{ND}}$ was estimated independently for each brain region.

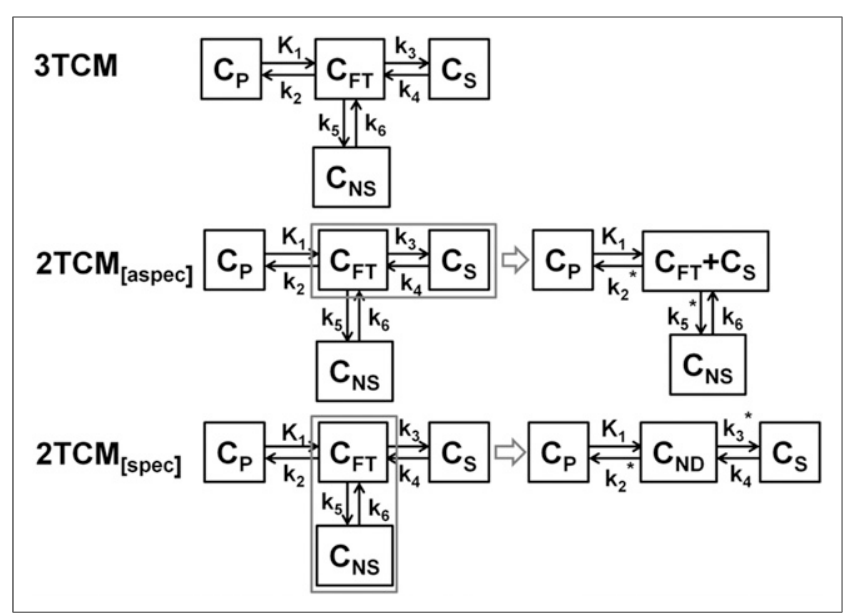

FIGURE 1. Schematic overview of 2 possible simplifications of 3TCM. For $2 \mathrm{TCM}_{\text {[aspec] }}$, compartments representing free and specific binding are merged, and remaining compartment represents nonspecific binding. Latter nonspecific binding is assumed constant for target and reference regions. For $2 \mathrm{TCM}_{[\mathrm{spec}}$, compartments representing free and nonspecific binding are merged to nondisplaceable tissue compartment, and remaining compartment represents specific binding. Former nondisplaceable compartment is assumed constant for reference and target regions. $\mathrm{C}_{\mathrm{FT}}=$ free tracer concentration; $\mathrm{C}_{\mathrm{ND}}=$ nondisplaceable tracer concentration; $\mathrm{C}_{\mathrm{NS}}=$ nonspecific tracer concentration; $\mathrm{C}_{\mathrm{P}}=$ plasma tracer concentration; $\mathrm{C}_{\mathrm{S}}=$ specific tracer concentration.

A third hypothesis, the possible confounding effect of a brainpenetrating radiometabolite on the quantification, was explored, where one compartment accounts for intact tracer kinetics $\left(1 \mathrm{TCM}_{[\text {intact] }}\right)$ and a second compartment describes the kinetics of a brain-entering radiometabolite. Intact tracer and metabolite kinetics were modeled using 2 separate parallel 1-tissue compartments with 2 separate parallel input functions. The first 1-tissue compartment with the arterial intact tracer input function described the specific and nonspecific binding of the intact tracer $\left(1 \mathrm{TCM}_{\text {[intact] }}\right)$, and the other 1-tissue compartment with the arterial metabolite input function was assumed to account for the brain uptake of radiometabolite. Again, assuming the radiometabolite fraction for the reference and target regions are the same, the distribution volume of the radiometabolite $\mathrm{V}_{\mathrm{T}, \mathrm{M}}$ was estimated for the frontal cortex and set to the same value for the nigrostriatal target regions. $\mathrm{V}_{\mathrm{T}, \mathrm{M}}$ determined with this model was compared with the distribution volume for nonspecific binding $\mathrm{V}_{\mathrm{NS}}$ obtained with $2 \mathrm{TCM}_{[\text {aspec] }}$ and with the fast metabolized fraction intact tracer in the arterial blood compartment.

$\mathrm{V}_{\mathrm{T}}$ values for $1 \mathrm{TCM}, 2 \mathrm{TCM}, 2 \mathrm{TCM}_{[\mathrm{spec}]}$, and $2 \mathrm{TCM}_{[\text {aspec] }}$ and the corresponding plasma to tissue uptake rates $K_{1}$ were evaluated. 1TCM, $2 \mathrm{TCM}, 2 \mathrm{TCM}_{[\mathrm{spec}]}$, and $2 \mathrm{TCM}_{[\text {aspec] }}$ fittings were compared using Akaike information criteria (AIC). $2 \mathrm{TCM} \mathrm{V}_{\mathrm{T}}$ values were used as reference values for further correlation analysis to assess a possible systematic bias of the outcome measure.

Binding Potential $\left(B P_{N D}\right)$ and Reference Tissue Models. Nondisplaceable $\mathrm{BP}_{\mathrm{ND}}$ using the simplified reference tissue model (SRTM) (19) and multilinear reference tissue model (MRTM) (20) were evaluated with the frontal cortex as reference tissue. The frontal cortex was considered the reference tissue of choice because it provided consistently the lowest values for $2 \mathrm{TCM} \mathrm{V} \mathrm{V}_{\mathrm{T}}, K_{1} / k_{2}$, and $\left(K_{1} / k_{2}\right) \times\left(k_{3} / k_{4}\right)$ when compared with other candidate reference tissues such as the thalamus and cerebellum (Fig. 2).

MRTM allows the fast generation of voxelwise parametric $\mathrm{BP}_{\mathrm{ND}}$ maps and therefore voxelwise statistical data comparison. For exploratory 


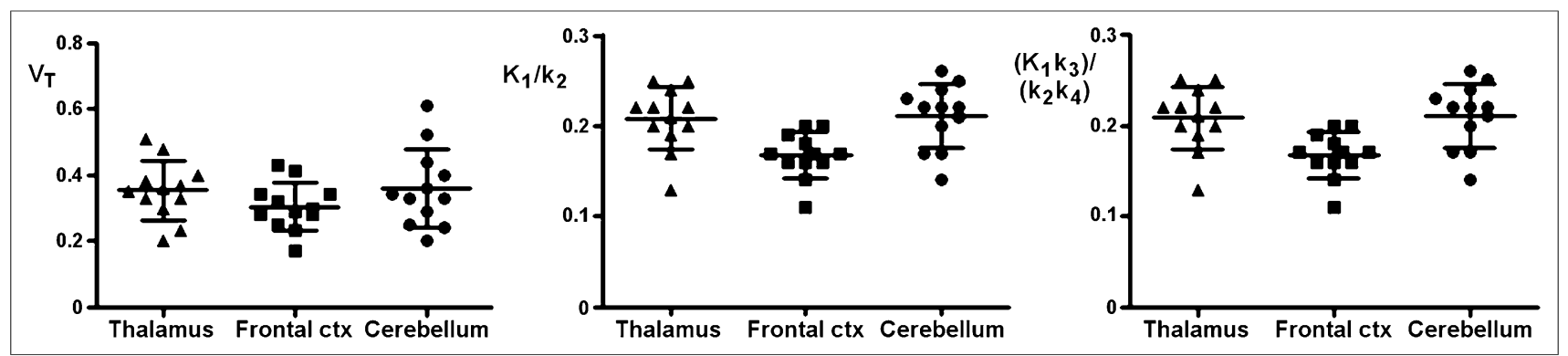

FIGURE 2. Overview of $\mathrm{V}_{\mathrm{T}}, K_{1} / k_{2}$, and $\left(K_{1} / k_{2}\right) \times\left(k_{3} / k_{4}\right)$ for $2 \mathrm{TCM}$ for candidate reference tissue regions thalamus, frontal cortex, and cerebellum. ctx $=$ cortex.

purposes, also the thalamus and cerebellum were considered as reference regions for SRTM and were compared with SRTM $\mathrm{BP}_{\mathrm{ND}}$ and AIC values using the frontal cortex.

For the target regions putamen, caudate nucleus, ventral striatum, and substantia nigra, $\mathrm{BP}_{\mathrm{ND}}$ values of the reference tissue models were compared with $\mathrm{BP}_{\mathrm{ND}}$ values of the full kinetic models 1TCM, 2TCM, $2 \mathrm{TCM}_{[\text {spec] }}, 2 \mathrm{TCM}_{\text {[aspec }]}$, and $1 \mathrm{TCM}_{\text {[intact] }}$. In the case of $1 \mathrm{TCM}$ and $2 \mathrm{TCM}, \mathrm{BP}_{\mathrm{ND}}$ was estimated as the $\mathrm{V}_{\mathrm{T}}$ ratio relative to the frontal cortex minus 1 , and for $2 \mathrm{TCM}_{[\text {spec] }}, \mathrm{BP}_{\mathrm{ND}}$ was calculated as the $\mathrm{V}_{\mathrm{S}}$ over $\mathrm{V}_{\mathrm{ND}}$ ratio. For $2 \mathrm{TCM}_{\text {[aspec] }}, \mathrm{BP}_{\mathrm{ND}}$ values were calculated relative to the frontal cortex while discarding the distribution volume for nonspecific binding. On the other hand, $\mathrm{BP}_{\mathrm{ND}}$ values for $1 \mathrm{TCM}_{\text {[intact] }}$ were determined by taking into account only the intact tracer distribution volume for target and reference tissue. In this way, the potential bias due to nonspecific binding or a brain-penetrating radiometabolite was avoided. $2 \mathrm{TCM}_{\text {[aspec] }} \mathrm{BP}_{\mathrm{ND}}$ values were considered reference values to allow correlation analysis and to assess possible over- or underestimation of the outcome measure.

Time Stability of Outcome Measures and Test-Retest Statistics. To determine the stability of the 1TCM and 2TCM $\mathrm{V}_{\mathrm{T}}$ and SRTM and MRTM BP $\mathrm{ND}_{\mathrm{ND}}$ estimates as functions of the acquisition time, reduced acquisition times of 90 and 60 min were evaluated and compared with a 135-min acquisition interval. For each of the reduced acquisition times, 1TCM and 2TCM AIC values were compared as well.

Test-retest variability (reproducibility) was assessed as the absolute variability VAR defined as $|\mathrm{x} 1-\mathrm{x} 2| /(\mathrm{x} 1+\mathrm{x} 2) \times 200$, where $\mathrm{x}$ refers to the parameter of interest. Test-retest reliability was evaluated in terms of the intraclass correlation coefficient (ICC), defined as (BSMS - WSMS)/(BSMS + WSMS), where BSMS is the betweensubject mean square and WSMS the within-subject mean square. The ICC ranges from 0 to 1 , with values closer to 1 indicating better reliability, which means that most variance is due to between-subject rather than within-subject variation.

\section{Statistical Analysis}

Statistical analysis was performed using Prism software (version 5.0; GraphPad Software). Parameters of interest were compared using 1-way repeated-measure ANOVA including Bonferroni multiplecomparison tests. When appropriate, a 2-tailed paired Student $t$ test was used. Correlation analysis was performed using a Spearman $\rho$ correlation coefficient. A $P$ value of 0.05 was considered a threshold criterion of statistical significance. Values are represented as mean \pm SD unless otherwise stated. The ratio between parameters was determined as the slope of linear regression analysis with the intercept set to zero.

\section{RESULTS}

\section{Brain Uptake and Plasma Metabolites}

Figure 3A shows orthogonal late standardized uptake value images (averaged over $60-90 \mathrm{~min}$ ) of ${ }^{18} \mathrm{~F}-\mathrm{JNJ}-42259152$ in a rep- resentative subject. Figure $3 \mathrm{~B}$ shows the corresponding timeactivity curves for the striatal regions, substantia nigra, thalamus, cerebellum, and medial frontal cortex. ${ }^{18} \mathrm{~F}-\mathrm{JNJ}-42259152$ exhibits relatively fast brain kinetics for the striatal regions, with a time to peak after bolus injection of 10-15 min, followed by a moderately fast washout. No subjective or objective adverse events during or after tracer administration were reported in any of the subjects.

Metabolite analysis identified 2 metabolites in plasma after $40 \mathrm{~min}, 1$ polar and 1 nonpolar metabolite, through cleavage of the ${ }^{18} \mathrm{~F}$-containing pyridine ring with fenol formation, both unlikely to pass the blood-brain-barrier. The fraction of radiometabolites of ${ }^{18} \mathrm{~F}-\mathrm{JNJ}-42259152$ in arterial plasma, as percentage of the intact fraction, is given in Figure 4. A fraction of $51.9 \% \pm 9.8 \%$ was metabolized, with a half-life of $18.7 \pm 7.6$ min constituting a fast metabolism component, whereas the remaining fraction was metabolized slowly, resulting in an approximately $50 \%$ fraction of intact tracer after $2 \mathrm{~h}$.

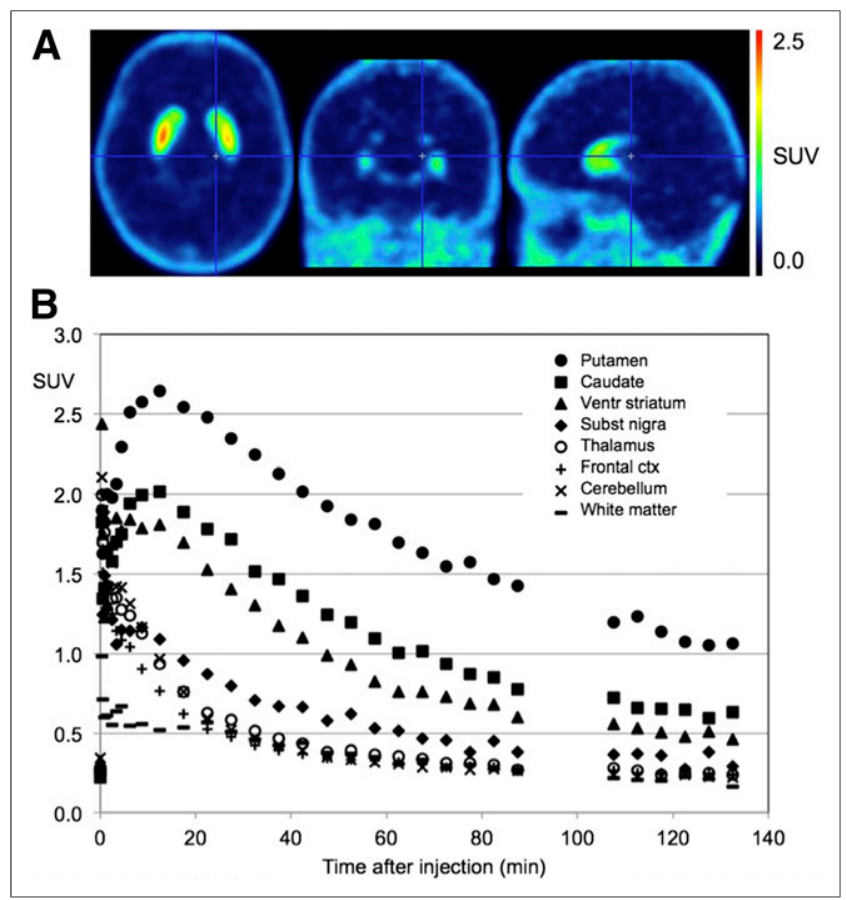

FIGURE 3. (A) Average standardized uptake value image (SUV) (averaged over 60- to 90 -min interval) for ${ }^{18} \mathrm{~F}-J \mathrm{NJ}-42259152$ in human brain. (B) Time-activity curves for putamen, caudate nucleus, ventral striatum, substantia nigra, thalamus, frontal cortex, cerebellum, and white matter. ctx $=$ cortex; ventr $=$ ventral. 


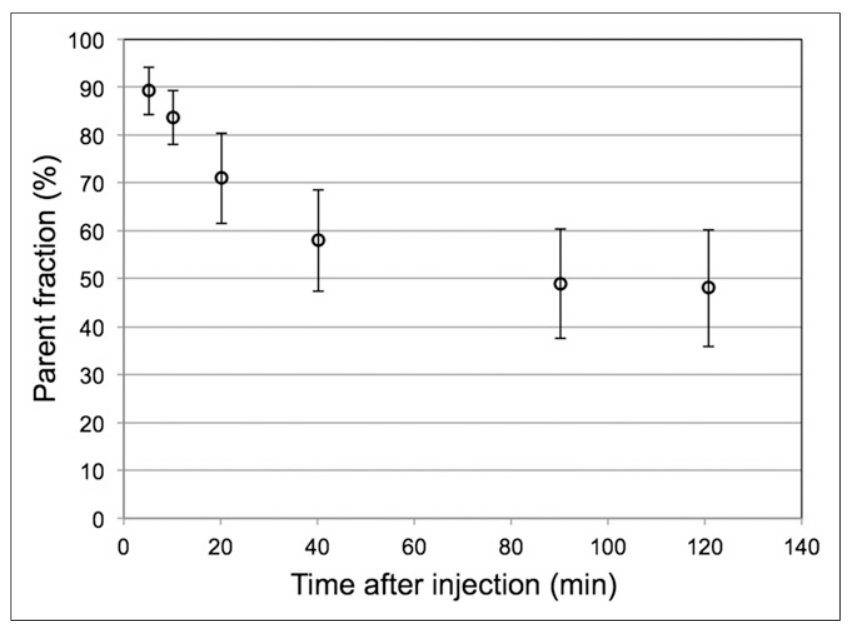

FIGURE 4. Fraction of intact ${ }^{18} \mathrm{~F}-\mathrm{JNJ}-42259152$ tracer in arterial plasma as function of time after injection.

\section{Kinetic Modeling}

Tissue Distribution Volume and Metabolite Kinetics. An overview of average $\mathrm{V}_{\mathrm{T}}$ for the considered models and brain regions is given in Figure 5. The fraction nondisplaceable binding $\mathrm{V}_{\mathrm{ND}}$ and specific binding $\mathrm{V}_{\mathrm{S}}$ is given for 2TCM and $2 \mathrm{TCM}_{[\text {spec] }}$ whereas for $2 \mathrm{TCM}_{[\text {aspec] }} \mathrm{V}_{\mathrm{T}}$ is subdivided in the fraction free and specifically bound tracer $\mathrm{V}_{\mathrm{FT}+\mathrm{S}}$ and nonspecific binding $V_{N S}$. A significant difference between $V_{T}$ values was found for all pairs of models, except between 2TCM and $2 \mathrm{TCM}_{[\text {aspec] }}$.

When the distribution volume of the intact tracer determined using $1 \mathrm{TCM}_{\text {[intact] }}$ and the distribution volume of the free and specifically bound tracer $\mathrm{V}_{\mathrm{FT}+\mathrm{S}}$ determined using $2 \mathrm{TCM}_{\text {[aspec] }}$ were compared, no significant difference was found. For $1 \mathrm{TCM}_{\text {[intact] }}$, the $\mathrm{V}_{\mathrm{T}, \mathrm{M}}$ was $0.16 \pm 0.05$, and $\mathrm{V}_{\mathrm{NS}}$ for $2 \mathrm{TCM}_{\text {[aspec] }}$ was $0.12 \pm 0.06$. There was a significant correlation between the $2 \mathrm{TCM}_{\text {[aspec] }} \mathrm{V}_{\mathrm{NS}}$ and $1 \mathrm{TCM}_{\text {[intact] }} \mathrm{V}_{\mathrm{T}, \mathrm{M}}$ values $(\rho=0.79)$ and between $2 \mathrm{TCM}_{[\text {aspec] }} \mathrm{V}_{\mathrm{NS}}$ and the fraction intact tracer $\mathrm{A}$ that was metabolized in the arterial blood compartment $(\rho=0.74)$.

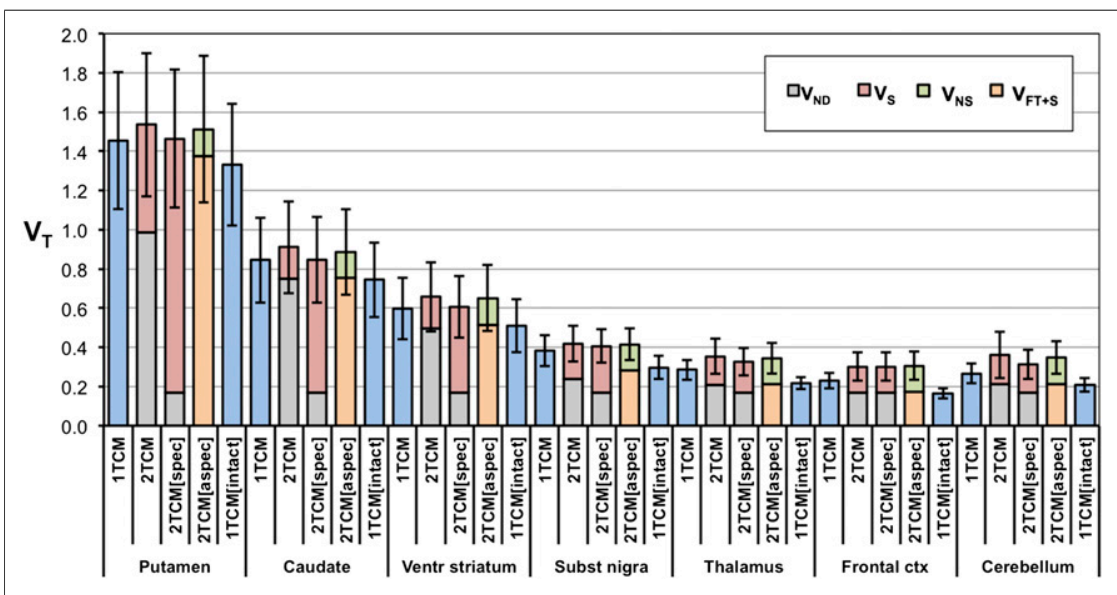

FIGURE 5. Obtained cerebral $\mathrm{V}_{\mathrm{T}}$ for ${ }^{18} \mathrm{~F}-\mathrm{JNJ}-42259152$ with $1 \mathrm{TCM}, 2 \mathrm{TCM}, 2 \mathrm{TCM}$ with constant nondisplaceable distribution volume $V_{N D}$ and variable distribution volume for specific binding $\mathrm{V}_{\mathrm{S}}\left(2 \mathrm{TCM}_{[\mathrm{spec}}\right)$, $2 \mathrm{TCM}$ with constant nonspecific distribution volume $\mathrm{V}_{\mathrm{NS}}$ and variable distribution volume for free tracer and specific binding $\mathrm{V}_{\mathrm{ft}+\mathrm{s}}\left(2 \mathrm{TCM}_{[\mathrm{aspec}]}\right)$, and $1 \mathrm{TCM}$ taking into account brain-penetrating radiometabolite $\left(\right.$ TCM $\left._{\text {[intact) }}\right)$ using 135-min acquisition time $(n=12)$.
$K_{1}$ values for the different models are summarized in Figure 6, and $K_{1}, k_{2}, k_{3}$, and $k_{4}$ values are presented in Table 1 for 1TCM and 2TCM. $K_{1}$ values differed significantly between all model pairs, except for the pairs $2 \mathrm{TCM}$ and $2 \mathrm{TCM}_{\text {[aspec] }}$ and $2 \mathrm{TCM}_{\text {[aspec] }}$ and $1 \mathrm{TCM}_{\text {[intact]. }}$.

Average AIC values for $1 \mathrm{TCM}, 2 \mathrm{TCM}, 2 \mathrm{TCM}_{[\text {spec] }}$, and $2 \mathrm{TCM}_{[\mathrm{aspec}]}$ were, respectively, $261.1 \pm 15.0,243.7 \pm 21.0$, $249.9 \pm 21.4$, and $245.7 \pm 23.9$. The AIC for the 1TCM was significantly higher than for the 2TCM. Furthermore, significant differences were found between the 2TCMs except between $2 \mathrm{TCM}$ and $2 \mathrm{TCM}_{\text {[aspec] }}$.

Table 2 gives an overview of the correlations between 2TCM $\mathrm{V}_{\mathrm{T}}$ and other models per brain region. The global $\mathrm{V}_{\mathrm{T}}$ ratios are given in Table 3. For all target regions, the correlation between models was excellent.

$B P_{N D}$ and Reference Tissue Models. An overview of average $\mathrm{BP}_{\mathrm{ND}}$ for the considered models and brain target regions is given in Figure 7. No significant $\mathrm{BP}_{\mathrm{ND}}$ differences were found among 2TCM, SRTM, and MRTM or between $2 \mathrm{TCM}_{[\text {aspec] }}$ and $1 \mathrm{TCM}_{[\mathrm{in}-}$ tact]. All other $\mathrm{BP}_{\mathrm{ND}}$ differences were significant. Table 2 summarizes the Spearman correlation coefficients separately for each target region, and Table 3 gives overall $\mathrm{BP}_{\mathrm{ND}}$ ratios, both using $2 \mathrm{TCM}_{[\text {aspec] }} \mathrm{BP}_{\mathrm{ND}}$ as a reference value.

When the thalamus and cerebellum were considered as reference tissues for SRTM, average $\mathrm{BP}_{\mathrm{ND}}$ values for the putamen, caudate nucleus, ventral striatum, and substantia nigra were, respectively, $2.78 \pm 0.47,1.35 \pm 0.31,0.77 \pm 0.23$, and $0.22 \pm$ 0.10 for the thalamus and, respectively, $2.91 \pm 0.44,1.43 \pm 0.36$, $0.84 \pm 0.34$, and $0.26 \pm 0.12$ for the cerebellum. Compared with the corresponding values $3.45 \pm 0.43,1.78 \pm 0.35,1.10 \pm 0.31$, and $0.44 \pm 0.09$ for the frontal cortex, $\mathrm{SRTM} \mathrm{BP}_{\mathrm{ND}}$ values referenced to the thalamus and cerebellum both differed significantly from those referenced to the frontal cortex whereas no significant difference was found between the thalamus and cerebellum. SRTM $\mathrm{BP}_{\mathrm{ND}}$ values using the thalamus and cerebellum relate to SRTM $\mathrm{BP}_{\mathrm{ND}}$ values using the frontal cortex by a factor 0.79 and 0.83 , respectively. In terms of correlation with $\mathrm{SRTM} \mathrm{BP}_{\mathrm{ND}}$ using the frontal cortex, spearman $\rho$ correlation coefficients of SRTM BP $\mathrm{ND}_{\mathrm{ND}}$ using thalamus and cerebellum were, respectively, 0.83 and 0.76 for the putamen, 0.92 and 0.80 for the caudate nucleus, 0.81 and 0.87 for the ventral striatum, and 0.64 and 0.52 for the substantia nigra. Overall correlation coefficient for both the thalamus and the cerebellum was 0.98 . All correlations were significant except the SRTM $\mathrm{BP}_{\mathrm{ND}}$ for the substantia nigra using the cerebellum. To compare reference regions in terms of model fitting, SRTM AIC values using the thalamus, frontal cortex, and cerebellum were, respectively, $239.1 \pm 17.4$, $240.5 \pm 16.7$, and $240.8 \pm 16.3$ and not significantly different.

Time Stability and Test-Retest of $V_{T}$ and $B P_{N D}$. The time stability of $\mathrm{V}_{\mathrm{T}}$ for $1 \mathrm{TCM}$ and 2TCM and of $\mathrm{BP}_{\mathrm{ND}}$ for SRTM and MRTM are given in Figure 8. 1TCM and $2 \mathrm{TCM} \mathrm{V}_{\mathrm{T}}$ values for the 135- and 90-min acquisition times were not significantly different contrary to $60-\mathrm{min} \mathrm{V}_{\mathrm{T}}$ values, which were significantly lower than those for the 135-min acquisition time. 2TCM was the preferred model for the 135-min 


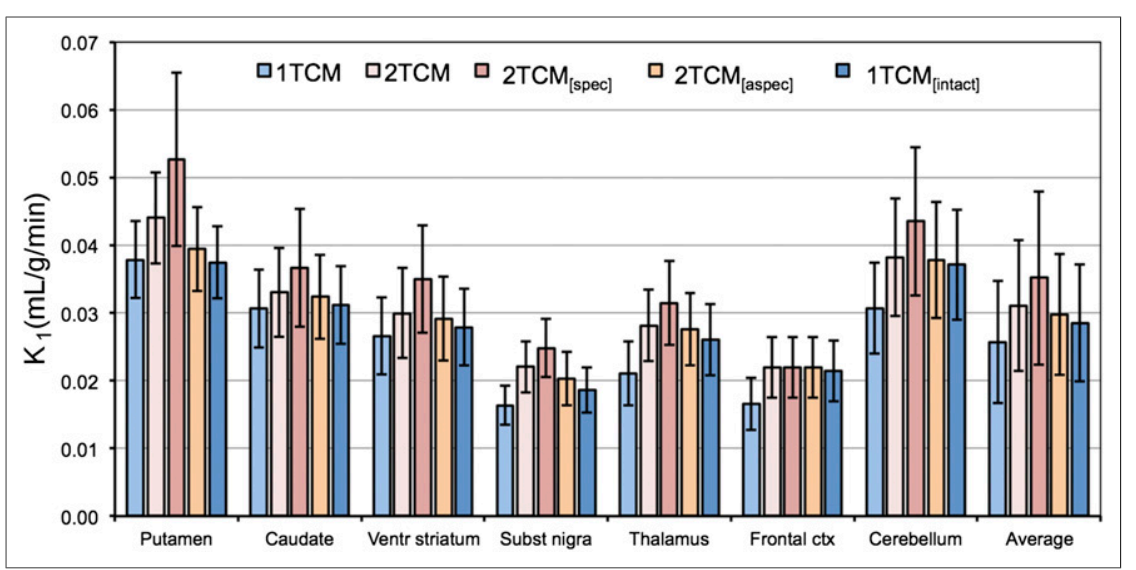

FIGURE 6. Plasma-to-tissue tracer uptake rate $\left(K_{1}\right)$ for ${ }^{18} \mathrm{~F}-\mathrm{JNJ}-42259152$ for 1 TCM, 2TCM, 2TCM with constant nondisplaceable distribution volume $\mathrm{V}_{\mathrm{ND}}$ and variable distribution volume for specific binding $\mathrm{V}_{\mathrm{S}}\left(2 \mathrm{TCM}_{\text {[spec] }}\right)$, 2TCM with constant nonspecific distribution volume $V_{\mathrm{NS}}$ and variable distribution volume for free tracer and specific binding $\mathrm{V}_{\mathrm{FT}+\mathrm{S}}$ $\left(2 \mathrm{TCM}_{\text {[aspec] }}\right)$, and $1 \mathrm{TCM}$ taking into account brain-penetrating radiometabolite $\left(1 \mathrm{TCM}_{[\text {intact] }}\right)$ using 135-min acquisition time $(n=12)$.

acquisition time, with a significantly lower AIC and significantly higher $\mathrm{V}_{\mathrm{T}}$ than 1TCM. Although 2TCM AIC (204.0 \pm 19.3$)$ is still significantly lower than 1TCM AIC $(212.7 \pm 12.1)$ for the 90 -min acquisition time, the situation is reversed for the 60-min acquisition time where-based on the lower AIC-1TCM $(64.0 \pm 15.4)$ is the preferred model over 2TCM $(69.9 \pm 15.5)$.

For MRTM and SRTM, $\mathrm{BP}_{\mathrm{ND}}$ values were slightly but significantly higher for the 90- and 60-min acquisition times than for the 135-min acquisition time. However, global correlations between $\mathrm{BP}_{\mathrm{ND}}$ values for the shorter times and the 135-min acquisition time were significant and excellent for both reference tissue models (Spearman $\rho \geq 0.94$ ).

Region-specific test-retest statistics for $\mathrm{V}_{\mathrm{T}}$ and $\mathrm{BP}_{\mathrm{ND}}$ are summarized in Table 4. No significant differences between the $V_{T}$ values of different compartmental models were found in terms of variability or ICC. In addition, no significantly different variability or ICCs were found for $\mathrm{BP}_{\mathrm{ND}}$ values determined with SRTM and MRTM.

\section{DISCUSSION}

The regional in vivo distribution of ${ }^{18} \mathrm{~F}-\mathrm{JNJ}-42259152$ in the brain was concordant with the known distribution of PDE10A from preclinical and histopathologic findings, with the highest activity in the putamen and in second order the caudate nucleus, ventral striatum, and substantia nigra. Cortical and cerebellar activity was more than 10 -fold lower than activity in the striatum. Previous studies using in situ hybridization and quantitative polymerase chain reaction have shown that levels in the cortex, cerebellum, and thalamus are 10- to 40-fold lower than in the striatum $(1,10)$. This finding indicates that, although expression levels outside the nigrostriatal region are low, they are not negligible and a careful evaluation of their use as a reference region is therefore warranted.

Tracer kinetics were first assessed using a standard 1TCM and 2TCM. Our findings indicated that the $2 \mathrm{TCM}$ is the preferred method to describe tracer kinetics, both for target and for potential reference regions. To determine whether 2TCM was more appropriate for potential reference regions because of low PDE10A expression in these regions, we constrained the distribution volume for nondisplaceable binding $\mathrm{V}_{\mathrm{ND}}$ for all brain regions to a constant value determined using the frontal cortex. In this way, $\mathrm{V}_{\mathrm{T}}$ differences between regions could be induced only by differences in specific binding. However, $\mathrm{V}_{\mathrm{T}}$ values of this constrained $2 \mathrm{TCM}_{[\mathrm{spec}]}$ approach were significantly different from unconstrained 2TCM fittings. Second, we assumed the presence of a nonspecific binding tissue compartment with slower tracer kinetics next to the free and specific binding tissue compartment with distribution volume $\mathrm{V}_{\mathrm{FT}+\mathrm{s}}$. Distribution volume for nonspecific binding $\mathrm{V}_{\mathrm{NS}}$ was estimated using a frontal cortex time-activity curve and constrained to this value for the other brain regions. The $\mathrm{V}_{\mathrm{T}}$ values of this constrained $2 \mathrm{TCM}_{\text {[aspec] }}$ approach were not significantly different from unconstrained $2 \mathrm{TCM}$ fittings. Moreover, AIC values of the $2 \mathrm{TCM}_{\text {[aspec] }}$ fittings were not significantly different from those of the 2TCM fittings. To determine whether this extra compartment was needed to model the nonspecific binding of a potential brain-penetrating radiometabolite instead of the intact tracer, we also modeled intact tracer kinetics with metabolite kinetics for the target and reference regions using 2 separate parallel 1-tissue compartments with 2 separate arterial input functions (i.e., intact tracer and radiometabolite input function $\left.\left[1 \mathrm{TCM}_{[\text {intact }]}\right]\right)$. For this approach, the tissue $\mathrm{V}_{\mathrm{T}, \mathrm{M}}$ was estimated using the frontal cortex and was constrained to

TABLE 1

Overview of Rate Constants of 1TCM and 2TCM for ${ }^{18}$ F-JNJ-42259152 and Different Brain Regions

\begin{tabular}{|c|c|c|c|c|c|c|c|c|}
\hline Model & Putamen & Caudate nucleus & Ventral striatum & Substantia nigra & Thalamus & Frontal cortex & Cerebellum & Global \\
\hline \multicolumn{9}{|l|}{$1 \mathrm{TCM}$} \\
\hline$K_{1}$ & $0.038 \pm 0.006$ & $0.031 \pm 0.006$ & $0.027 \pm 0.006$ & $0.016 \pm 0.003$ & $0.021 \pm 0.005$ & $0.017 \pm 0.004$ & $0.031 \pm 0.007$ & $0.026 \pm 0.009$ \\
\hline$k_{2}$ & $0.027 \pm 0.004$ & $0.037 \pm 0.005$ & $0.045 \pm 0.006$ & $0.044 \pm 0.008$ & $0.075 \pm 0.015$ & $0.073 \pm 0.013$ & $0.117 \pm 0.032$ & $0.060 \pm 0.032$ \\
\hline \multicolumn{9}{|l|}{$2 \mathrm{TCM}$} \\
\hline$K_{1}$ & $0.044 \pm 0.006$ & $0.033 \pm 0.007$ & $0.030 \pm 0.007$ & $0.022 \pm 0.004$ & $0.028 \pm 0.005$ & $0.022 \pm 0.004$ & $0.038 \pm 0.009$ & $0.031 \pm 0.010$ \\
\hline$k_{2}$ & $0.050 \pm 0.017$ & $0.046 \pm 0.011$ & $0.063 \pm 0.015$ & $0.094 \pm 0.015$ & $0.136 \pm 0.010$ & $0.131 \pm 0.011$ & $0.182 \pm 0.038$ & $0.100 \pm 0.051$ \\
\hline$k_{3}$ & $0.035 \pm 0.047$ & $0.005 \pm 0.006$ & $0.010 \pm 0.009$ & $0.026 \pm 0.012$ & $0.012 \pm 0.004$ & $0.010 \pm 0.004$ & $0.008 \pm 0.004$ & $0.015 \pm 0.021$ \\
\hline$k_{4}$ & $0.044 \pm 0.028$ & $0.029 \pm 0.043$ & $0.028 \pm 0.023$ & $0.035 \pm 0.012$ & $0.019 \pm 0.007$ & $0.015 \pm 0.007$ & $0.014 \pm 0.007$ & $0.026 \pm 0.024$ \\
\hline
\end{tabular}

Data are mean $\pm \mathrm{SD}$. 
TABLE 2

Correlation Coefficients for Different Models for ${ }^{18} \mathrm{~F}-J N J-42259152$ Versus 2TCM

\begin{tabular}{|c|c|c|c|c|c|c|c|c|}
\hline \multirow[b]{2}{*}{ Model } & \multicolumn{8}{|c|}{ Spearman correlation coefficients } \\
\hline & Putamen & Caudate nucleus & Ventral striatum & Substantia nigra & Thalamus & Frontal cortex & Cerebellum & Global \\
\hline \multicolumn{9}{|l|}{$\mathrm{V}_{\mathrm{T}}$} \\
\hline 1TCM & 1.00 & 0.83 & 0.90 & 0.91 & 0.85 & 0.85 & 0.84 & 0.96 \\
\hline $2 \mathrm{TCM}_{[\mathrm{spec}]}$ & 0.99 & 0.83 & 0.90 & 0.97 & 0.97 & 1.00 & 0.97 & 0.99 \\
\hline $2 \mathrm{TCM}_{\text {[aspec] }}$ & 0.96 & 0.79 & 0.75 & 0.97 & 0.95 & 1.00 & 0.78 & 0.98 \\
\hline $1 \mathrm{TCM}$ [intact] & 0.99 & 0.86 & 0.89 & 0.73 & 0.62 & $(0.54)$ & 0.76 & 0.93 \\
\hline \multicolumn{9}{|l|}{$\mathrm{BP}_{\mathrm{ND}}$} \\
\hline 1TCM & 0.73 & 0.79 & 0.65 & 0.60 & & & & 0.98 \\
\hline 2TCM & $(0.51)$ & $(0.34)$ & $(0.36)$ & 0.94 & & & & 0.94 \\
\hline $2 \mathrm{TCM}_{[\mathrm{spec}]}$ & 0.95 & 0.90 & 0.95 & $(0.42)$ & & & & 0.98 \\
\hline $1 \mathrm{TCM} \mathrm{M}_{[\text {intact] }}$ & 0.96 & 0.86 & 0.85 & 0.72 & & & & 0.99 \\
\hline $\mathrm{SRTM}_{[\mathrm{FCx}]}$ & $(0.57)$ & 0.82 & 0.70 & 0.64 & & & & 0.97 \\
\hline $\operatorname{MRTM}_{[\mathrm{FCx}]}$ & 0.61 & 0.81 & 0.71 & 0.64 & & & & 0.97 \\
\hline
\end{tabular}

Acquisition interval of 135 min was used $(n=12)$. Values in parentheses indicate nonsignificant correlations $(P \geq 0.05)$. For reference tissue models, frontal cortex was used as reference region.

$\mathrm{SRTM}_{[\mathrm{FCx}]}=\mathrm{SRTM}$ with frontal cortex (FCx) as reference tissue; MRTM with frontal cortex (FCx) as reference tissue.

this value for the other brain regions, to be able to estimate the distribution volume of the intact tracer for each brain region. No significant difference was observed between intact tracer $V_{T}$ and $\mathrm{V}_{\mathrm{F}+\mathrm{S}}$. Furthermore, significant correlations were found between $\mathrm{V}_{\mathrm{T}, \mathrm{M}}$ and $\mathrm{V}_{\mathrm{NS}}$ and between $\mathrm{V}_{\mathrm{NS}}$ and the fraction of metabolites in the arterial plasma compartment. Because there was evidence from preclinical experiments of a brain-penetrating radiometabolite in rodents (17), the current findings can be compatible also with a radiometabolite that is entering the brain, which could be a confounding factor for tracer quantification. Nevertheless, these findings also proved that both approaches were essentially the same and that metabolite kinetics could be modeled as nonspecific binding using only an intact tracer arterial input function.

Although possibly biased by a brain-penetrating radiometabolite, significant $\mathrm{V}_{\mathrm{T}}$ correlations were found with the standard 1TCM and 2TCM approach for all regions. For the target regions, correlations were still significant between $\mathrm{V}_{\mathrm{T}}$ using a $2 \mathrm{TCM}$ approach and $\mathrm{V}_{\mathrm{T}}$ of the intact tracer, demonstrating that in any case there is a reproducible bias of the tentative radiometabolite on tracer quantification.

Plasma-to-tissue uptake rates $K_{1}$ (Table 2) are relatively low, with significantly lower values due to poorer fittings for the 1TCM than 2TCM approach. These $K_{1}$ values are comparable to tracers such as ${ }^{18} \mathrm{~F}$-fluorodopa (population average $K_{1}, 0.03 \mathrm{~mL} / \mathrm{g} / \mathrm{min}$ ) (21), meaning that tracer uptake is perfusion independent. Although in general this can have the possible disadvantage of low signal because of the limited tracer uptake, the current spatial restriction to the striatum, with excellent signal-to-background ratio, indicates that an accurate quantification is feasible.

Because $2 \mathrm{TCM}_{[\text {aspec] }}$ accounts for nonspecific binding of either intact tracer or radiometabolite and provided similar $\mathrm{V}_{\mathrm{T}}$ and $\mathrm{AIC}$ values as unconstrained $2 \mathrm{TCM}$ fittings, $\mathrm{BP}_{\mathrm{ND}}$ calculated as the ratio $\mathrm{V}_{\mathrm{FT}+\mathrm{S}}$ minus 1 relative to the frontal cortex was used as a reference value. As expected, no significant difference was found between these $\mathrm{BP}_{\mathrm{ND}} 2 \mathrm{TCM}_{\text {[aspec] }}$ reference values and $\mathrm{BP}_{\mathrm{ND}}$ calculated as the $1 \mathrm{TCM}_{\text {[intact] }}$ tracer $\mathrm{V}_{\mathrm{T}}$ ratio minus 1 relative to the frontal cortex. Although SRTM and MRTM $\mathrm{BP}_{\mathrm{ND}}$ values were significantly lower than the reference values because the radiometabolite uptake or nonspecific binding is included when determining the reference tissue $\mathrm{BP}_{\mathrm{ND}}$ values, $\mathrm{SRTM}$ and MRTM $\mathrm{BP} \mathrm{PD}_{\mathrm{ND}}$ showed good correlations with the $2 \mathrm{TCM}_{[\mathrm{aspec}]}$ reference values for the different target regions. Only the $\mathrm{SRTM} \mathrm{BP}_{\mathrm{ND}}$ correlation for the putamen was borderline not significant, with a $P$ value of 0.055 .

Concerning the use of the thalamus and cerebellum as reference tissues for SRTM, both regions proved to be acceptable alternatives, with $\mathrm{BP}_{\mathrm{ND}}$ values that correlated significantly with those for the frontal cortex (except for the substantia nigra), although $\mathrm{BP}_{\mathrm{ND}}$ values were significantly different.

For $1 \mathrm{TCM}, \mathrm{V}_{\mathrm{T}}$ was stable down to $60 \mathrm{~min}$, with a significant negative bias of 5.5\%. For 2TCM, a more pronounced significant negative bias of $14 \%$ was noticed. 2TCM fittings became less stable for reduced acquisition times whereas for the 60-min acquisition time, differences between $1 \mathrm{TCM}$ and $2 \mathrm{TCM} \mathrm{V}_{\mathrm{T}}$ became

TABLE 3

Global Ratio of $\mathrm{V}_{\mathrm{T}}$ and $\mathrm{BP}_{\mathrm{ND}}$ for ${ }^{18} \mathrm{~F}-\mathrm{JNJ}-42259152$

\begin{tabular}{lccccccc}
\hline Ratio type & $1 \mathrm{TCM}$ & $2 \mathrm{TCM}$ & $2 \mathrm{TCM}_{[\mathrm{spec}]}$ & $2 \mathrm{TCM}_{\text {[aspec] }}$ & 1TCM $_{\text {[intact] }}$ & $\mathrm{SRTM}_{[\mathrm{FCx}]}$ & $\mathrm{MRTM}$ [FCx] \\
\hline $\mathrm{V}_{\mathrm{T}}$ & 0.93 & 1.0 & 0.95 & 0.98 & 0.82 & - \\
$\mathrm{BP}_{\mathrm{ND}}$ & 0.73 & 0.56 & 1.10 & 1.0 & 0.98 & 0.48 & 0.49
\end{tabular}

For reference tissue models, frontal cortex was used as reference region. Acquisition interval of 135 min was used ( $n=12$ ). $\mathrm{SRTM}_{[\mathrm{FCx}]}=\mathrm{SRTM}$ with frontal cortex $(\mathrm{FCx})$ as reference tissue; MRTM with frontal cortex $(\mathrm{FCx})$ as reference tissue. 


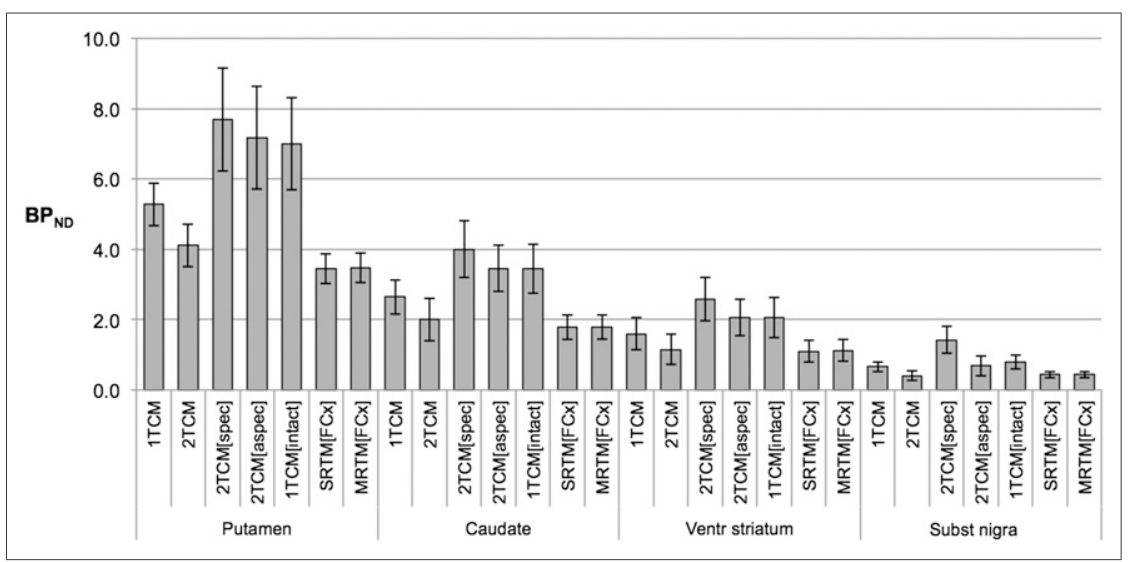

FIGURE 7. $\quad \mathrm{BP}_{\mathrm{ND}}$ for ${ }^{18} \mathrm{~F}-\mathrm{JNJ}-42259152$ for target regions putamen, caudate nucleus, ventral striatum, and substantia nigra, using frontal cortex as reference region. For 1TCM and $2 \mathrm{TCM}, \mathrm{BP}_{\mathrm{ND}}$ was estimated as ratio minus 1. For $2 \mathrm{TCM}$ with constant nondisplaceable distribution volume $V_{N D}$ and variable distribution volume for specific binding $V_{S}\left(2 T_{C M} M_{[s p e c}\right)$, $\mathrm{BP}_{\mathrm{ND}}$ was calculated ratio of $\mathrm{V}_{\mathrm{S}}$ over $\mathrm{V}_{\mathrm{ND}}$. For $2 \mathrm{TCM}$ with constant nonspecific distribution volume $V_{N D}$ and variable distribution volume for free tracer and specific binding $V_{F T+S}$ $\left(2 \mathrm{TCM}_{[\mathrm{aspec}]}\right), \mathrm{BP}_{\mathrm{ND}}$ values were calculated discarding nonspecific binding. $\mathrm{BP}_{\mathrm{ND}}$ values for $1 \mathrm{TCM}$ taking into account brain-penetrating radiometabolite $\left(1 \mathrm{TCM}_{\text {[intact] }}\right)$ consider only intact tracer distribution volume. $\mathrm{BP}_{\mathrm{ND}}$ for SRTM and MRTM are reported as well. All values are estimated for 135-min acquisition time $(n=12)$.

insignificant and 1TCM was the preferred model with the lower AIC. These findings are in agreement with the assumption that 2TCM accounts for a compartment with slow kinetics representing either nonspecific tracer binding or radiometabolite brain uptake.

When the small positive bias for SRTM and MRTM (both $4 \%$ for $90 \mathrm{~min}$ and $5 \%$ for $60 \mathrm{~min}$ ) is taken into account, we can conclude that 60 - to 90 -min dynamic acquisition should be sufficient to allow accurate quantification with SRTM or MRTM using the frontal cortex as a reference tissue.

In terms of long-term (weeks) test-retest, all models presented similar statistics, with repeatability values of 5\%-20\% for $\mathrm{V}_{\mathrm{T}}$ and $5 \%-12 \%$ for $\mathrm{BP}_{\mathrm{ND}}$. Although ICC values were within acceptable range, overall variability was relatively high and should be considered when comparing intersubject $\mathrm{V}_{\mathrm{T}}$ and $\mathrm{BP}_{\mathrm{ND}}$ values. ICC values were lower for the reference tissue models than for the compartmental models because of the lower between-subject variability. Variability was higher for compartmental models than for reference tissue models, probably because of added variability induced by arterial sampling and radiometabolite fraction corrections.

Concerning the limitations of the study and possible future perspectives, it needs to be emphasized that in the current design there was no independent reference available to provide an objective assessment of quantitative accuracy of the all proposed kinetic models. However, 3 different scenarios were considered: a brainpenetrating metabolite, nonspecific binding with slower kinetics, and a fraction of specific binding (because low nonzero PDE10A expression has been documented in histologic postmortem studies) in candidate reference regions such as the frontal cortex. Independent of the real underlying physiologic phenomenon, the kinetic models that take into account these different scenarios provide highly correlated quantitative endpoints that are also highly correlated with the standard and more straightforward reference tissue models. Therefore, future PET dose-occupancy studies (enzyme-blocking studies) are needed to allow a better estimate of the nondisplaceable binding of the tracer and to con- firm or exclude one of the before-mentioned scenarios. PET dose-occupancy studies will also provide a better insight into the regional and interindividual differences of nondisplaceable binding and justify use of reference tissue models as quantitative models. Furthermore, the small extraction fraction of the tracer with high affinity and accumulation in the striatum might cause some concern that delivery could be rate-limiting. This issue needs to be addressed in future studies and by comparison to other radioligands that are currently under development.

\section{CONCLUSION}

We successfully characterized kinetic modeling of the PDE10A tracer ${ }^{18} \mathrm{~F}-\mathrm{JNJ}$ 42259152 in the human brain. ${ }^{18} \mathrm{~F}-\mathrm{JNJ}$ 42259152 currently is the only published PDE10A PET tracer with good characteristics for human studies. A potential metabolite contribution in brain uptake cannot be excluded, although nonspecific binding of the intact tracer can be an alternative explanation for the observed kinetic behavior. In any case, this contribution is small and reproducible. Therefore, a 90-min dynamic acquisition and a reference tissue approach with the frontal cortex as reference tissue provides a reproducible and accurate estimation of $\mathrm{BP}_{\mathrm{ND}}$, allowing more feasible quantitative studies in neuropsychiatric study populations.

\section{DISCLOSURE}

The costs of publication of this article were defrayed in part by the payment of page charges. Therefore, and solely to indicate this fact, this article is hereby marked "advertisement" in accordance with 18 USC section 1734. Koen Van Laere is Senior Clinical Fellow for the Flemish Science Foundation (FWO), Belgium.

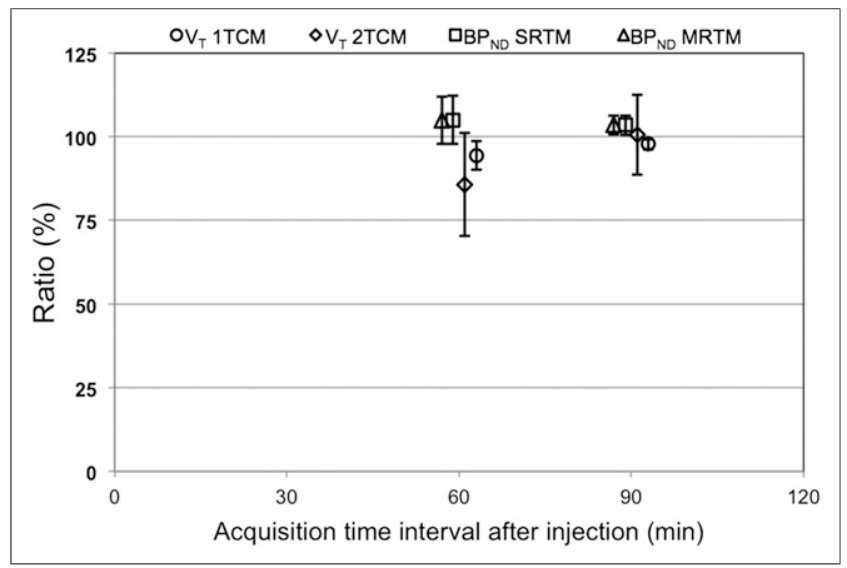

FIGURE 8. Induced bias and variance of reduced acquisition times of 60 and 90 min for ${ }^{18} \mathrm{~F}-\mathrm{JNJ}-42259152$, relative to acquisition time of $135 \mathrm{~min}$. This is shown both for $\mathrm{V}_{\mathrm{T}}$ of $1 \mathrm{TCM}$ and $2 \mathrm{TCM}$ and for $\mathrm{BP}_{\mathrm{ND}}$ values of SRTM and MRTM using frontal cortex as reference tissue. 
Kristof Dubois and Mark E. Schmidt are employees of Janssen Pharmaceutica R\&D, Belgium. No other potential conflict of interest relevant to this article was reported.

\section{ACKNOWLEDGMENTS}

We thank Kwinten Porters and Mieke Steukers and the clinical PET radiopharmacy team for their skilled help. Janssen Pharmaceutica is gratefully acknowledged for the supply of the precursor and reference molecule.

\section{REFERENCES}

1. Seeger TF, Bartlett B, Coskran TM, et al. Immunohistochemical localization of PDE10A in the rat brain. Brain Res. 2003;985:113-126.

2. Tu Z, Fan J, Li S, et al. Radiosynthesis and in vivo evaluation of $\left[{ }^{11} \mathrm{C}\right] \mathrm{MP}-10$ as a PET probe for imaging PDE10A in rodent and non-human primate brain. Bioorg Med Chem. 2011;19:1666-1673.

3. Bender AT, Beavo JA. Cyclic nucleotide phosphodiesterases: molecular regulation to clinical use. Pharmacol Rev. 2006;58:488-520.

4. Fujishige K, Kotera J, Omori K. Striatum- and testis-specific phosphodiesterase PDE10A isolation and characterization of a rat PDE10A. Eur J Biochem. 1999; 266:1118-1127.

5. Surmeier DJ, Ding J, Day M, Wang Z, Shen W. D1 and D2 dopamine-receptor modulation of striatal glutamatergic signaling in striatal medium spiny neurons. Trends Neurosci. 2007;30:228-235.

6. Nishi A, Kuroiwa M, Miller DB, et al. Distinct roles of PDE4 and PDE10A in the regulation of cAMP/PKA signaling in the striatum. $J$ Neurosci. 2008;28: 10460-10471.

7. Schmidt CJ, Chapin DS, Cianfrogna J, et al. Preclinical characterization of selective phosphodiesterase 10A inhibitors: a new therapeutic approach to the treatment of schizophrenia. J Pharmacol Exp Ther. 2008;325:681-690.

8. Grauer SM, Pulito VL, Navarra RL, et al. Phosphodiesterase 10A inhibitor activity in preclinical models of the positive, cognitive, and negative symptoms of schizophrenia. J Pharmacol Exp Ther. 2009;331:574-590.

9. Siuciak JA, McCarthy SA, Chapin DS, et al. Genetic deletion of the striatumenriched phosphodiesterase PDE10A: evidence for altered striatal function. Neuropharmacology. 2006;51:374-385.

10. Hebb AL, Robertson HA, Denovan-Wright EM. Striatal phosphodiesterase mRNA and protein levels are reduced in Huntington's disease transgenic mice prior to the onset of motor symptoms. Neuroscience. 2004;123:967-981.

11. Menniti FS, Faraci WS, Schmidt CJ. Phosphodiesterases in the CNS: targets for drug development. Nat Rev Drug Discov. 2006;5:660-670.

12. Plisson C, Salinas C, Weinzimmer D, et al. Radiosynthesis and in vivo evaluation of $\left[{ }^{11} \mathrm{C}\right] \mathrm{MP}-10$ as a positron emission tomography radioligand for phosphodiesterase 10A. Nucl Med Biol. 2011;38:875-884.

13. Tu Z, Xu J, Jones LA, Li S, Mach RH. Carbon-11 labeled papaverine as a PET tracer for imaging PDE10A: radiosynthesis, in vitro and in vivo evaluation. Nucl Med Biol. 2010;37:509-516.

14. Celen S, Koole M, De Angelis M, et al. Preclinical evaluation of ${ }^{18}$ F-JNJ41510417 as a radioligand for PET imaging of phosphodiesterase-10A in the brain. $\mathrm{J} \mathrm{Nucl}$ Med. 2010;51:1584-1591.

15. Andrés JI, De Angelis M, Alcazar J, et al. Synthesis, in vivo occupancy, and radiolabeling of potent phosphodiesterase subtype-10 inhibitors as candidates for positron emission tomography imaging. J Med Chem. 2011;54:5820-5835.

16. Van Laere K, Ahmad RU, Hudyana H, et al. Human biodistribution and dosimetry of ${ }^{18} \mathrm{~F}-\mathrm{JNJ} 42259152$, a radioligand for phosphodiesterase 10A imaging. Eur J Nucl Med Mol Imaging. 2013;40:254-261.

17. Celeus S, Koole M, Ooms M, et al. Preclinical evaluation of [18F-]JNJ-422J9152 as a PET tracer for PDE10A. Neuroimage. In press.

18. Innis RB, Cunningham VJ, Delforge J, et al. Consensus nomenclature for in vivo imaging of reversibly binding radioligands. J Cereb Blood Flow Metab. 2007; 27:1533-1539.

19. Lammertsma AA, Hume SP. Simplified reference tissue model for PET receptor studies. Neuroimage. 1996;4:153-158.

20. Ichise M, Liow JS, Lu JQ, et al. Linearized reference tissue parametric imaging methods: application to $\left[{ }^{11} \mathrm{C}\right] \mathrm{DASB}$ positron emission tomography studies of the serotonin transporter in human brain. J Cereb Blood Flow Metab. 2003;23: 1096-1112.

21. Morrish PK, Rakshi JS, Bailey DL, Sawle GV, Brooks DJ. Measuring the rate of progression and estimating the preclinical period of Parkinson's disease with $\left[{ }^{18}\right.$ F]dopa PET. J Neurol Neurosurg Psychiatry. 1998;64:314-319. 